University of Zurich

Department of Economics

Working Paper Series

ISSN 1664-7041 (print)

ISSN 1664-705X (online)

Working Paper No. 84

Redistributive Preferences, Redistribution, and Inequality: Evidence from a Panel of OECD Countries

Andreas Kuhn

July 2012 


\title{
Redistributive Preferences, Redistribution, and Inequality: Evidence from a Panel of OECD Countries
}

\author{
Andreas Kuhn, University of Zurich and IZA*
}

July 2012

\begin{abstract}
This paper describes individuals' inequality perceptions, distributional norms, and redistributive preferences in a panel of OECD countries, primarily focusing on the association between these subjective measures and the effective level of inequality and redistribution. Not surprisingly, the effective level of redistribution (after tax-and-transfer inequality) is positively (negatively) correlated with redistributive preferences. There is also evidence showing that the subjective and objective dimension of inequality and redistribution are, at least partially, linked with individuals' political preferences and their voting behavior. The association between objective and subjective measures of inequality and redistribution vanishes, however, once more fundamental country characteristics are taken into account. This suggests that these characteristics explain both redistributive preferences as well as the effective level of redistribution and after tax-and-transfer inequality.
\end{abstract}

JEL classification: D31; D63; J31

Keywords: inequality perceptions; distributional norms; redistributive preferences; inequality; redistribution; political preferences

${ }^{*}$ I thank Rafael Lalive, Andrew Oswald, and Josef Zweimüller for helpful discussions at an early stage of this project. I also thank Simon Büchi, Sandro Favre, and Andreas Steinhauer for superb research assistance. Financial support by the Austrian Science Fund (FWF) is gratefully acknowledged (S 10304-G16: "The Austrian Center for Labor Economics and the Analysis of the Welfare State").

Contact: Andreas Kuhn, University of Zurich, Department of Economics, Mühlebachstrasse 86, 8008 Zurich, Switzerland; +41 (0)44 63437 26; andreas.kuhn@econ.uzh.ch. 


\section{Introduction}

The redistribution of income and wealth is an issue of utmost economic and political significance, as a substantial amount of resources is redistributed in all OECD member countries. In the mid-2000s, for example, overall public cash benefits amounted to $15.8 \%$, and household taxes to $31.1 \%$ of average household income among working age people (OECD, 2008). Even more remarkably, public cash benefits (as a percentage of household income) among working age individuals range from a low of about $6 \%$ in the United States to a high of as much as $30 \%$ in Poland, while household taxes range from a low of about $21 \%$ in Ireland to a high of about $54 \%$ in Denmark and Iceland. Looking at these numbers, it is both important and natural to ask why countries differ so much with respect to the amount of resources that are redistributed and, consequently, the level of after tax-and-transfer inequality. ${ }^{1}$

It seems very natural to take country differences in redistributive preferences as a starting point when trying to explain the variation in the effective level of redistribution across countries. Indeed, many researchers appear to share the view that individuals' subjective perceptions and attitudes play an important role in explaining the observed country differences in inequality and redistribution. For example, Alesina and Angeletos (2005, p.960) argue that "(...) the difference in political support for redistribution appears (...) to reflect a difference in social perceptions regarding the fairness of market outcomes and the underlying sources of income inequality". Such arguments are backed by empirical evidence from Alesina et al. (2001), for example, who show that there is a close relationship between social expenditure and the belief that luck is important in determining one's income at the aggregate level. Consistent with this evidence, some recent theoretical papers have forcefully pushed the idea that individuals' redistributive preferences and the effective amount of redistribution should be viewed as simultaneously determined and thus in equilibrium, at least in the short-run. In Piketty (1995), individuals imperfectly learn about the relative importance of effort and luck in determining their own income from their own experience and, depending on their beliefs, decide on their preferred tax rate. The optimal level of effort will in turn depend on the chosen tax rate. The

\footnotetext{
${ }^{1}$ See Doerrenberg and Peichl (2012) for an econometric analysis of the association between explicit redistributive policies (e.g. public social expenditure) and the reduction in income inequality effectively attained.
} 
setup is similar in the model of Alesina and Angeletos (2005), where different beliefs about the relative role of ascribed versus acquired characteristics in determining individual earnings lead voters to choose different tax rates. The tax rate, in turn, will determine the monetary return on individual effort. The effective return on individual effort will then either reinforce or weaken the belief in the relative importance of individual effort. The basic setup is similar in the model of Bénabou and Tirole (2006), where individuals feel a need to believe in a just world because such a belief helps them convince themselves, and/or their children, that personal effort will pay off. If a majority of individuals ends up with such beliefs, they will implement a low tax rate. At the same time, if individuals expect taxes to be low, this will strengthen their belief that individual effort will ultimately materialize. One important common feature of these models is that multiple equilibria are possible, and thus they are all able to reproduce the stylized distinction between Europeans and Americans, i.e. a "European" equilibrium where the belief is prevalent that luck determines income, with a high demand for redistribution, and consequently a high level of redistribution; as well as an "American" equilibrium where the belief in one's effort is prevalent, with a low level of redistributive preferences, and with a correspondingly low amount of redistribution.

Somewhat surprisingly, however, empirical evidence on the association between redistributive preferences and the effective level of redistribution is quite limited. ${ }^{2}$ One of the available studies using cross-country data is Corneo and Grüner (2002). Even they do not mainly focus on differences across countries, they do present some evidence suggesting that there are large differences in redistributive preferences across different countries. Specifically, they find large differences in redistributive preferences between former socialist countries and Western democracies. Probably the most comprehensive descriptive evidence on country differences in redistributive preferences to date comes from Osberg and Smeeding (2006). Interestingly, they show that there are many more features in the variation of redistributive preferences across countries than the contrast between the US and Europe. For example, they show that there is more polarization of attitudes and less concern for reducing wage differentials at the bottom

\footnotetext{
${ }^{2}$ Most of the available empirical studies focus on the determinants of individual-level preferences for redistribution, most often only using data from one single country (e.g. Alesina and Giuliano, 2009; Alesina and La Ferrara, 2005; Fong, 2001; Ravallion and Lokshin, 2000).
} 
of the wage distribution among Americans than among Europeans. While they use a similar conceptual framework to that which I use in this paper, they do not relate country differences in their measure of redistributive preferences to differences in objective measures of inequality or redistribution. Isaksson and Lindskog (2009) focus on cross-country variation in the effect of social norms on preferences for redistribution. They find that the association between redistributive preferences and social norms differs widely across countries, and that these differences explain part of the observed country differences in redistributive preferences. Again, however, they do not relate their subjective measure of redistributive preferences with some objective measure of either the effective level of inequality or the effective level of redistribution.

This paper builds on and extends the existing empirical literature using internationally comparable survey data covering eighteen different OECD member countries (regions within the same country in a few cases, such as former East and West Germany) and three different points in time (i.e. 1987, 1992, and 1999). Moreover, the empirical analysis is based on a simple yet intuitive conceptual framework which is almost ideally suited for tackling the following issues, which also present the main contributions of this paper. First, it presents extensive empirical evidence for this significant group of countries on the hypothesized association of individuals' subjective perceptions of inequality and distributional norms with the effective level of inequality and the effective extent of redistribution. At the aggregate level, I find that the difference in the Gini coefficient of disposable household income before and after taxes and transfers, total public social expenditure, as well as after tax-and-transfer household income inequality are strongly and significantly associated with individuals' redistributive preferences. Second, this paper provides evidence on how these two dimensions might be linked together at the individual level. Specifically, I show that there is a strong association between individuals' subjective evaluations of inequality and their more general political preferences, such as their support for progressive taxation. Third and finally, my empirical analysis also shows that this association vanishes once additional, and arguably more fundamental country characteristics, such as specific political institutions or ethnic fractionalization, are taken into account. Taken together, these results suggest that while redistributive preferences and the effective level of redistribution are in a short-run equilibrium, they are both ultimately driven by more fundamental national 
characteristics such as a country's political institutions.

The remainder of this paper is organized as follows. The next section presents the main data source. Section 3 briefly describes the conceptual framework. Section 4 presents descriptive evidence on the diversity of inequality perceptions and distributional norms both across countries and over time. Section 5 provides econometric evidence on the hypothesized association between subjective and objective inequality measures, as well as on the association between subjective inequality measures and individuals' more general political preferences, representing one potential mechanism linking the two dimensions. Section 6 concludes.

\section{Data}

I primarily rely on data from three surveys on the causes and consequences of social inequality administered by and available from the International Social Survey Program (ISSP). ${ }^{3}$ The first survey on social inequality was run in 1987, the second in 1992, and the third followed in 1999. Moreover, a fourth survey was administered in 2009, but these data are not yet (but should soon be) available to researchers. The number of participating countries has steadily increased over time. While only ten countries participated in the first survey, the number of participating countries has increased steadily and about thirty countries participated in the 1999 survey. Because of restricted data availability for some additional aggregate-level variables, I had to restrict the analysis to 21 OECD member countries (or, in a few cases, regions within the same country, such as East and West Germany). Moreover, because the number of participating countries has steadily increased over time, the data are unbalanced on the longitudinal dimension and I end up with a maximum of 38 observations in the aggregate level analysis. Table 1 shows the number of available observations, both at the individual and the aggregate levels.

\section{Table 1}

\footnotetext{
${ }^{3}$ The ISSP is a collaboration of various national survey organizations which administers one survey a year with an alternating core theme such as religion, work orientations, or social inequality. See the organization's homepage for more information: www.issp.org.
} 
I will use some additional, aggregate-level variables from various other sources, such as aggregate income or the effective level of inequality (measured as the Gini coefficient in disposable household income, either before or after taxes and transfer payments) in the empirical analysis. These additional variables, and their sources, are listed in appendix table A.1, along with some basic descriptives.

\section{Conceptual Framework}

In will now discuss how to construct subjective measures of inequality perceptions and distributional norms, as well as a measure of individuals' normative assessment of market justice, drawing on a simple conceptual framework proposed by and discussed in more detail in Kuhn (2011). The framework is fundamentally based on individuals' subjective wage estimates for people working in different occupations, such as a bus driver, a skilled worker in a factory, or a doctor in general practice (see appendix B for the exact wording of the questions and additional details).

\subsection{Objective Wages}

The natural starting point is the conventional measurement of objective wage inequality, however. One of the most routinely used and best known inequality measures is the Gini coefficient. The computation of the Gini coefficient is usually based on individual-level wage data, but it is possible to approximate the individual-level Gini coefficient using group-level data on wages (e.g. Gastwirth and Glauberman, 1976). Indeed, observing wage information for only two distinct groups of individuals suffices in principle for approximating the underlying inequality of individual wages.

Formally, assume that there are only two distinct, mutually exclusive, and exhaustive groups of wage earners (labeled bottom and top group, respectively, below) and that we observe the following information describing the distribution of wages across these two groups:

$$
y \equiv\left(\bar{y}_{\text {bottom }}, \bar{y}_{\text {top }}, f_{\text {bottom }}\right)
$$


with $\bar{y}_{\text {bottom }}$ and $\bar{y}_{\text {top }}$ denoting the average wage within the bottom and the top group of wage earners, respectively, and with $f_{\text {bottom }}$ denoting the fraction of the population that belongs to the bottom group. ${ }^{4}$ The Gini coefficient in this simplified setup turns out to be equal to the difference between the population share of the bottom group and the wage share of the bottom group (see Kuhn, 2011): ${ }^{5}$

$$
G=f_{\text {bottom }}-q_{\text {bottom }}
$$

In the scenario with only two distinct groups of wage earners, the Gini coefficient is thus simply given by the difference between the population share and the wage share of the bottom group.

\subsection{Subjective Wage Estimates}

The simplified setup formalized by equations (1) and (2) can also be applied to the case of subjective wage estimates which are available from the ISSP data, subject to two modifications. The first modification is due to the fact that there are two conceptually distinct wage estimates from an individual's subjective point of view: actual and ethical wage estimates. While actual wage estimates refer to wages that people perceive to actually prevail within a given group, ethical wage estimates refer to wages they would judge as legitimate the same given group. ${ }^{6}$ The second modification is simply due to the fact that both actual and ethical wage estimates will usually differ across individuals. This implies that the wage shares of the two groups, and thus subjective inequality measures in general, become individual-specific quantities. ${ }^{7}$ We

\footnotetext{
${ }^{4}$ Because there are only two groups of wage earners, and because these two groups represent the overall population of wage earners, the two population shares must add up to one. This implies that the two population shares are given by $f_{\text {bottom }}$ and $\left(1-f_{\text {bottom }}\right)=f_{\text {top }}$, respectively.

${ }^{5}$ Note that the average wage in the population is given by $\bar{y}=\bar{y}_{\text {bottom }} \cdot f_{\text {bottom }}+\bar{y}_{\text {top }} \cdot f_{\text {top }}$. This implies that the wage share of the bottom group is given by $q_{\text {bottom }}=\left(f_{\text {bottom }} \cdot \bar{y}_{\text {bottom }}\right) / \bar{y}$, and thus that the Gini coefficient can be computed based on the information contained in vector $y$ alone. Moreover, it is always the case that $\bar{y}_{\text {bottom }} \leq \bar{y}_{\text {top }}$ for objective wage data. Thus $q_{\text {bottom }}$ is always smaller than or equal to $f_{\text {bottom }}$ and, consequently, $G$ always lies between 0 and $f_{\text {bottom }}$.

${ }^{6}$ The conceptual distinction between individuals' inequality perceptions and their distributional norms is prevalent in the sociological literature; see Jasso (1980) or Osberg and Smeeding (2006) among many others.

${ }^{7}$ Even though one can imagine that individuals also have different perceptions and/or norms about the population shares of the two groups, I will treat them as fixed parameters, which simply implies that $f_{\text {bottom }}$ does not vary across individuals. The main reason for doing so is that there is no adequate information in the survey which could be used to plausibly approximate individuals' perceptions of population shares. Moreover, treating $f_{\text {bottom }}$ as a fixed parameter also makes it possible to exclusively focus on differences in wage estimates
} 
thus end up with two distinct distributions of inequality indices in the case of subjective wage estimates, while it is possible to measure objective wage inequality with one single number only.

Formally, assume that the following two triplets of information are observed for each respondent - perfectly analogous to the case of objective wage information, besides the two modifications discussed above (compare with equation (1)):

$$
\begin{aligned}
& y(i)^{\text {actual }} \equiv\left(\bar{y}(i)_{\text {bottom }}^{\text {actual }}, \bar{y}(i)_{\text {top }}^{\text {actual }}, f_{\text {bottom }}\right), \quad \text { and } \\
& y(i)^{\text {ethical }} \equiv\left(\bar{y}(i)_{\text {bottom }}^{\text {ethical }}, \bar{y}(i)_{\text {top }}^{\text {ethical }}, f_{\text {bottom }}\right),
\end{aligned}
$$

with $y(i)^{\text {actual }}$ denoting the set of information that describes an individual's perception of the actual wage distribution and with $y(i)^{\text {ethical }}$ referring to those wages that she would judge as fair. $^{8}$ Based on (3a) and (3b), respectively, the corresponding individual-level Gini coefficients can be easily computed as follows:

$$
\begin{aligned}
& G(i)^{\text {actual }}=f_{\text {bottom }}-q(i)_{\text {bottom }}^{\text {actual }}, \quad \text { and } \\
& G(i)^{\text {ethical }}=f_{\text {bottom }}-q(i)_{\text {bottom }}^{\text {ethical }},
\end{aligned}
$$

where $q(i)_{\text {bottom }}^{\text {actual }}$ denotes the actual share of the total wage bill going to the bottom group and $q(i)_{\text {bottom }}^{\text {ethical }}$ denotes the wage share that the bottom group judges as fair. Thus, as in the case of objective wage data, the Gini coefficient is simply given by the difference between the population share of the bottom group and the wage share of the bottom group. ${ }^{9} G(i)^{\text {actual }}$ and $G(i)^{\text {ethical }}$ represent, respectively, individual perceptions of inequality in market wages and distributional norms with respect to market wages (inequality perceptions and distributional norms, for short).

since, if $f_{\text {bottom }}$ is treated as a fixed parameter across individuals, all variation in the two subjective inequality measures must be due to variation in subjective wage estimates.

${ }^{8}$ Appendix B details how the different components of equations (3a) and (3b) can be estimated from individual-level wage estimates for people working in different occupations that are available in the ISSP data.

${ }^{9}$ In principle, the two subjective Gini coefficients can take on negative values (in contrast to the Gini coefficient describing objective wage data) because some individuals may think that the wage share of the bottom group is actually larger than their population share (i.e. $q(i)_{\text {bottom }}^{w}$ can take on any value between zero and one). As shown in table 2 below, this is indeed true for a tiny fraction of the sample $(0.1 \%$ in the case of actual and $0.5 \%$ in the case of ethical wage estimates). 
If both inequality perceptions and distributional norms are observed for the same individual, it is also possible to define an individual's redistributive preferences as her desired relative reduction in the perceived level of inequality in market wages:

$$
R(i)=\left(1-\frac{G(i)^{\text {ethical }}}{G(i)^{\text {actual }}}\right)
$$

with $G(i)^{\text {actual }}$ and $G(i)^{\text {ethical }}$ as defined in equation (4a) and (4b), respectively. Note that a positive demand for some equalization of market wages can only arise if the evaluation of ethical wages differs from the perceived distribution of market wages. ${ }^{10}$ Finally, note that $R(i)$ measures only the potential demand for redistribution because the measure does not directly imply that individuals actually desire that the distribution of market wages be adjusted according to their evaluations. Thus, while $R(i)$ is directly informative about the discrepancy between individuals' perceptions of actual wage inequality and their normative views of the fair distribution of wages, it is not necessarily informative regarding their beliefs that something should be done to eliminate this discrepancy, or even more specifically that the state should intervene correspondingly. It may thus be more appropriate to think of $R(i)$ as a measure of individuals' normative assessment of market justice, or rather the absence of market justice, with values of $R(i)$ close to (far from) zero indicating a strong (weak) belief in market justice.

\section{The Diversity of Inequality Perceptions, Distributional}

\section{Norms, and Redistributive Preferences}

\subsection{Main Distributional Features}

I first present some simple descriptive statistics related to individuals' inequality perceptions and their distributional norms in the data pooled across all countries and years, fleshing out the most important distributional features of the two subjective inequality indices and redistributive preferences.

\footnotetext{
${ }^{10}$ Note that the demand for equalization of market wages can take on negative values, namely if the ethical inequality index is larger the perceived inequality index. The demand for equalization of market wages can also be larger than one if either $G(i)^{\text {actual }}$ or $G(i)^{\text {ethical }}$ takes on a negative value (cf. footnote 9 ).
} 
Table 2

These statistics are shown in table 2. Panel (a) first shows the estimated fraction of individuals (in any given country and survey year) who are classified as belonging to the bottom group of wage earners, $f_{\text {bottom }}$. The estimated population share of the bottom group equals $77 \%$ on average, varying between a low of about 57\% (Canada, 1992) to a high of almost 92\% (Poland, 1992). The average actual wage share of the bottom (top) group amounts to $42 \%$ (58\%), while the average ethical wage share is about $54 \%$ (about $46 \%) .{ }^{11}$

Panel (b) shows descriptives for the two subjective inequality indices. Average inequality perception equals 0.451 across all countries/regions and years. Also note that there is not one single individual who does not perceive any wage differentials at all (this is indicated by the fact that the fraction of individuals who perceive the wages of the bottom group to be the same as the wages of the top group is zero). At the same time, average ethical inequality only amounts to 0.301 , i.e. the ethical level of inequality is about a third lower than the perceived level. Moreover, note that only few individuals (less than 1\%) judge absolute equality as fair, as can be seen from the fraction of individuals with an ethical inequality of zero. ${ }^{12}$

Panel (c) shows that people favor a more equal distribution of market wages across occupations than the distribution they perceive to actually exist (on average by about one-third). Indeed, the overwhelming majority (roughly 90\%) of individuals has a positive demand for some equalization of wages, while only a small fraction of the sample has no or even a negative demand for equalizing market wages (about $8.2 \%$ and $1.6 \%$, respectively). ${ }^{13}$ At the same time, table 2 also shows that only a few individuals (less than 1\%) would like to eliminate all differences in wages across different occupations (i.e. have a demand for equalization of market

\footnotetext{
${ }^{11}$ One interesting feature not evident in table 2 is the fact that the overall ethical wage is on average lower than the overall actual wage in most countries and years.

${ }^{12}$ It seems worth mentioning that the overall averages of the two subjective Gini coefficients are surprisingly close to mean levels of inequality before and after taxes and transfers, respectively (see appendix table A.1). While I certainly do not want to stress this feature too much, not the least because subjective measures relate to individual wages while the objective measures relate to household incomes, the similarity between mean inequality perceptions and inequality before taxes and transfers does suggest that individuals appear to have, on average, relatively realistic perceptions of wages for people working in different occupations. See also Osberg and Smeeding (2006) on this issue.

${ }^{13} \mathrm{~A}$ negative demand for equalizing market wages is suggestive of a desired regressive transfer. In most cases, however, a negative value simply results from an individual's desire to increase both the wage of the bottom and the top group, but with a larger desired relative increase for the top group (note that overall perceived wages may be different from overall ethical wages; cf. footnote 11).
} 
wages exactly equal to one).

\subsection{Differences Across Regions and Countries}

I will next look at differences in these measures across broadly defined regions, as well as over countries within these regions, and across time. Indeed, one of the most recurrent themes in the existing literature is the pronounced difference between Europe and the US regarding redistributive preferences (e.g. Alesina and Glaeser, 2004; Alesina et al., 2001). I thus start with a comparison between the Anglo-American and the European countries (while separating Eastern and Western European countries, however).

\section{Figure 1}

The upper three panels of figure 1 show density estimates of inequality perceptions, distributional norms, and redistributive preferences for each the three regions. The densities differ markedly, and in the expected direction, from each other for each of the three measures. First, as shown in panel (a), individuals in the Anglo-American countries perceive much higher wage inequality than both Eastern and Western Europeans. The figure also shows, however, that the distribution of inequality perceptions among Eastern Europeans is very different from those of Western Europeans. Panel (b) shows that Europeans are much less tolerant towards inequality than individuals from Anglo-American countries, but also that the tolerated wage inequality is lowest among Eastern Europeans. Regarding redistributive preferences, panel (c) shows that individuals from the Anglo-American countries indeed have the lowest demand for equalization of market wages, and that Western Europeans tend to have less demand for equalization of market wages than Eastern Europeans.

However, as Osberg and Smeeding (2006) and others point out, there is considerable heterogeneity among European and Anglo-American countries as well. The remaining three panels of figure 1 illustrate the heterogeneity in perceptions and beliefs across countries within the three broader regions. Each panel shows country-specific density estimates of the demand for equalization of market wages (similar regional variation is found for the two subjective inequality measures; results not shown, however). Only two countries within each region are specifically 
marked for better readability. Panel (d) shows density estimates among the group of Western European countries. In this region, Sweden and Switzerland represent the two extreme distributions, while the remaining countries all fall somewhere between these two countries. Correspondingly, East Germany and Hungary represent the two extremes among the Eastern European countries, shown in panel (e), and so do Northern Ireland and the United States within the group of Anglo-American countries, as shown in panel (f). Interestingly, it also appears that there is more heterogeneity in redistributive preferences across both Western and Eastern Europe than among the group of the Anglo-American countries.

\subsection{Distributional Shifts Across Time}

Because there are surveys from three different years (i.e. 1987, 1992, and 1999) focusing on questions of social inequality, it is also possible to assess whether individuals' perceptions and normative beliefs have changed over time. However, because only few countries participated in all three surveys, the significance of the corresponding evidence remains somewhat limited. Figure 2 shows density estimates of the demand for equalization of market wages and the two subjective inequality indices, respectively, by year of survey. ${ }^{14}$

\section{Figure 2}

The first two panels of figure 2 show substantial shifts over time in the distribution of both inequality perceptions and distributional norms. Specifically, inequality perceptions have unambiguously increased over time, as shown in panel (a). This upward shift in inequality perceptions parallels the evolution of the effective level of inequality in most OECD countries (e.g. Atkinson, 2008). ${ }^{15}$ At the same time, however, panel (b) shows that the ethical level of inequality has also risen, thus counteracting the upward trend in the perceived level of wage inequality. This is an interesting result, suggesting that the increase in the effective level of inequality was paralleled by a shift towards increasing tolerance to inequality in market

\footnotetext{
${ }^{14}$ For drawing this figure I restrict the sample to observations from those countries/regions that participated in all three surveys: Australia, West Germany, Great Britain, Hungary, and the United States.

${ }^{15}$ Also note that there was a bimodal distribution in 1987 that vanished over time. The bimodality is driven by Hungary, the only Eastern European country that participated in the 1987 survey. This in turn implies that subjective evaluations in Hungary must have converged towards the distribution of the other countries over time.
} 
wages. In fact, several authors have argued that such changes in social norms are one important component in understanding the recent rise income inequality (Atkinson, 2003; Levy and Temin, 2007; Piketty and Saez, 2006). Because the distribution of both subjective inequality indices tends to shift upwards over time, they partially cancel each other. As a result, there is actually not much change in the distribution of redistributive preferences over time, as shown in panel (c) of figure 2 .

\section{Redistributive Preferences and the Effective Level of Inequality and Redistribution}

\subsection{Baseline Estimates}

The next step is to see whether these differences in inequality perceptions, distributional norms, and redistributive preferences across countries and over time are systematically related to corresponding differences in objective measures of redistribution and/or after tax-and-transfer inequality. I begin my examination of this issue by running a series of simple regression models that take the following basic form:

$$
\begin{aligned}
& \omega_{j t}=\beta_{0}+\bar{R}_{j t} \beta_{1}+\epsilon_{j t}, \quad \text { or } \\
& \omega_{j t}=\beta_{0}+\bar{G}_{j t}^{\text {actual }} \beta_{2}+\bar{G}_{j t}^{\text {ethical }} \beta_{3}+\epsilon_{j t},
\end{aligned}
$$

with the dependent variable $\omega_{j t}$ being either the difference between the Gini coefficient in disposable household income before and after taxes and transfer payments, $\Delta G_{j t}$, total social expenditure as a percentage share of GDP, $\operatorname{SocExp}_{i t}$, or simply the Gini coefficient in disposable

household income after taxes and transfer payments, $G_{j t}^{\text {after }}$ in country $j$ and year $t$. For the moment, the only regressor in most of the specifications shown is the average demand for redistribution within country/region $j$ and year $t$, denoted by $\bar{R}_{j t}$, and thus the parameter of key interest in most cases is given by $\beta_{1}$ (see equation (6a)). In some of the specifications, however, I include the mean values of the two subjective inequality indices as main regressors, as indicated by equation (6b). In this case, parameters $\beta_{2}$ and $\beta_{3}$ are of main interest. The 
resulting parameter estimates, for both kind of specification, are given in table 3 .

\section{Table 3}

The first column shows parameter estimates from a regression of $\Delta G_{j t}$ on $\bar{R}_{j t}$ only. The regression yields a statistically significant point estimate of 0.373 ( $\mathrm{t}$-value of about 2.56). Note that the estimated coefficient on $\bar{R}_{j t}$ implies a substantive quantitative association between redistributive preferences and the difference in the Gini coefficient. In fact, the approximate elasticity of $\Delta$ Gini with respect to redistributive preferences equals about $0.74(=(0.373$. 0.319)/0.161). The specification in the second column includes country $\times$ year means of the two subjective inequality indices, $\bar{G}_{j t}^{\text {actual }}$ and $\bar{G}_{j t}^{\text {ethical }}$, instead of average redistributive preferences. Both coefficients have the expected sign, with a positive coefficient on inequality perceptions and a negative coefficient on distributional norms, and even though they are both insignificant individually, they are jointly significant (see the corresponding F-statistic shown in the bottom row of table 3 ).

The next two columns show analogous regression specifications for SocExp $\operatorname{Es}_{i t}$ as dependent variable, arguably a more direct measure of redistribution than $\Delta G_{j t}$. As above, however, there is a large positive and significant association between redistributive preferences and overall social expenditure. The approximate elasticity is equal to about $0.5(=(33.451 \cdot 0.319) / 21.253)$ in this case, smaller than in the case of $\Delta G_{j t}$, but still surprisingly large. There is also a similar pattern when inequality perceptions and distributional norms are included as regressors, as shown in the fourth column. There is a positive but insignificant effect of inequality perceptions and a negative and significant effect of distributional norms on total social expenditure.

The remaining columns of table 3 show results using the after tax-and-transfer inequality in disposable household income, $G_{j t}^{\text {after }}$, as the dependent variable. In the fifth column, both $\bar{R}_{j t}$ and $G_{j t}^{\text {before }}$ are included as regressors. The resulting point estimate on $\bar{R}_{j t}$ in this specification equals -0.352 (with a t-value of about -3.14). Note that, holding inequality before taxes and transfers constant, a negative effect of redistributive preferences on the Gini coefficient after taxes and transfers is consistent with a positive association between redistributive preferences and the difference between inequality before and after taxes/transfers. The sixth column shows, however, that virtually the same estimate results if only $\bar{R}_{j t}$ is included as regressor. The 
corresponding estimates suggest that redistributive preferences and the Gini coefficient before taxes/transfers are only weakly correlated with each other. I again include the two subjective inequality indices instead of redistributive preferences in the seventh column. As before, the corresponding point estimates are insignificant individually, but the overall F-statistic shows that they are jointly significant. Even though they are both insignificant, both coefficients have the expected sign (a positive sign for inequality perceptions and a negative sign in the

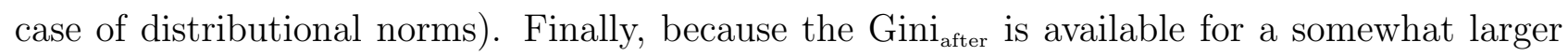
sample than the Gini $_{\text {before }}$, and because the comparison between the specifications from the fifth and the sixth column shows that the estimated parameter on $\bar{R}_{j t}$ is almost the same, irrespective of whether $G_{j t}^{\text {before }}$ is (also) included as regressor, it is possible to use a slightly larger sample if Gini $_{\text {before }}$ is excluded from the set of regressors (i.e. the sample increases from 35 to 38 observations; see table 1). Not surprisingly, using this extended sample yields a somewhat different point estimate on redistributive preferences $\left(\widehat{\beta_{1}}=-0.208\right)$, but one that is not statistically different from that obtained from the smaller sample.

\subsection{Subjective Inequality Measures and Individuals' Political Pref- erences}

A closely related question is how individual-level inequality perceptions, distributional norms, and redistributive preferences are linked to the effective level of inequality and redistribution in the short run. There are various potential channels linking subjective and objective measures of inequality and redistribution, but the most likely channel runs from individuals' redistributive preferences to their more general political preferences and their voting behavior (e.g. Borck, 2007). In this part of the analysis, I will thus focus on the empirical association between subjective inequality measures and individuals' more general political preferences such as their support for progressive taxation.

Since I can rely on individual-level data in this case, it is possible to apply a standard twoway fixed-effects regression specification to estimate the strength of the association between 
individuals' political preferences and their subjective inequality evaluations:

$$
p_{i j t}=\beta_{0}+x_{i j t} \beta+\omega_{i j t} \alpha+\psi_{j}+\lambda_{t}+\varepsilon_{i j t},
$$

where the dependent variable $p_{i j t}$ is one of three distinct measures of individuals' more general political preferences: either individuals' stated support for redistribution by the state, their support for progressive taxation, or a self-assessment of their general political orientation on a simple scale running from far-left to far-right, labeled conservative political orientation below (see appendix A for the exact wording of the underlying survey questions). All specifications either include the two subjective inequality measures or, alternatively, individuals' assessment of market justice, denoted by $\omega_{i j t}$. Moreover, all specifications include a set of individual-level controls, denoted by $x_{i t}$, as well as a full set of country and survey-year fixed effects, denoted by $\psi_{j}$ and $\lambda_{t}$, respectively. ${ }^{16}$

\section{Table 4}

Parameter estimates are shown in 4 . The first two columns of table 4 shows results for individuals' general support for redistribution by the state. The first column shows that those individuals with a high demand for equalization of market wages tend to be more likely to support the redistribution by the state. The corresponding point estimate is statistically significant and moreover large in substantial terms. Specifically, evaluated at sample means, the elasticity of the support for redistribution by the state with respect to the demand for equalization of market wages amounts to about $0.125(=(0.319 \cdot 0.255) / 0.65)$. The two subjective inequality indices also yield significant point estimates, as shown in the second column. The corresponding elasticities are about 0.258 and -0.256 , respectively.

The next two columns show analogous results for individuals' support for progressive taxation. The third column shows a strong and statistically significant association between redistributive preferences and individuals' support for progressive taxation. This shows that

\footnotetext{
${ }^{16}$ The full list of individual-level control variables is as follows: a set of four variables describing an individual's beliefs about the factors that determine and that should determine one's income, an individual's rank within the income distribution within country $j$ and year $t$, an index of experienced social mobility in the past ten years, an individuals' perception of social conflicts, and a few standard socio-demographic controls such as age or education. See appendix A for additional details.
} 
individuals with a high demand for equalizing market wages are clearly more in favor of progressive taxation than those with a low demand. Again, the size of the estimated coefficients is remarkably large, even though much smaller than in the case of one's general support for redistribution by the state. The elasticity of support for progressive taxation with respect to redistributive preferences amounts to 0.047. Not surprisingly, the two subjective inequality measures are also significantly associated with the support for progressive taxation, as shown in the fourth column.

Finally, the last two columns report results for individuals' political self-assessment on a simple left-right scale, where higher values on the scale denote a more conservative orientation. As expected, individuals with a higher demand for equalizing market wages are less likely to think of themselves as having a conservative orientation. Again, besides being statistically significant, the estimated coefficient turns out to be large in substantive terms. The elasticity of conservative orientation with respect to the demand for equalization of market wages is -0.156, while the elasticities with respect to the mean of actual and ethical inequality equal -0.328 and 0.323 , respectively.

\subsection{Controlling for Additional Country Characteristics}

Taken together, the empirical evidence presented so far is clearly consistent with the view that we observe different equilibria of redistributive preferences and the effective level of redistribution across countries and time, with a high (low) demand for redistribution going hand in hand with a high (low) effective level of redistribution and a low (high) level of after tax-and-transfer inequality. There is also evidence that redistributive preferences (alternatively, inequality perceptions and distributional norms) are linked to the effective, aggregate level of inequality and redistribution though individuals' more general political preferences and their voting behavior.

In the medium and longer run, however, one also needs to explain why countries end up in one equilibrium and not the other. This will immediately shift our focus to more fundamental, and often non-economic, factors such as a country's political institutions. For example, in a comprehensive review of the theoretical literature and the empirical evidence explaining the different social security systems of the US and Europe, Alesina and Glaeser (2004, p.3) 
conclude that "(...) economic considerations alone do not go very far in explaining American exceptionalism". More specifically, they argue that political institutions and ethnic diversity, rather than purely economic factors, are the key to ultimately understand the difference between the US and Europe in terms of after tax-and-transfer inequality and redistribution. I will thus next examine if the simple association between redistributive preferences and the effective level of inequality/redistribution still holds if arguably more fundamental country characteristics are taken into account.

In the following, given the somewhat limited degrees of freedom available for the aggregatelevel analysis, I restrict myself to a few variables that have been prominently discussed in the existing literature and mainly follow the empirical analysis done by Alesina et al. (2001) and Alesina and Glaeser (2004). One factor that has received a lot of attention among economists is the before tax-and-transfer inequality in income, hypothesized to have a positive effect on the extent of redistribution (e.g. Borge and Ratts $\varnothing, 2004$; Milanovic, 2000). ${ }^{17}$ The age distribution in the population has also been suggested as an important explanatory factor, since many redistributive policies are mechanically linked to the age distribution in the population; pensions are the most prominent example of this (Galasso and Profeta, 2007; Razin et al., 2002; Tabellini, 2000). Another well-known hypothesis is that countries that are more open to trade redistribute more because they are exposed to more aggregate income volatility. It is hypothesized that these countries therefore use redistributive policies to insure individuals against the increased risk of negative income shocks (e.g. Rodrik, 1998). Moreover, several researchers have argued that additional, non-economic factors are even more important for our understanding of country differences in after tax-and-transfer inequality and redistribution. Among the factors identified as most important are features of a country's political institutions and especially the existence of proportional representation (e.g. Alesina and Glaeser, 2004; Alesina et al., 2001). It has also been shown that ethnic fractionalization of the electorate has a strong negative impact on the extent of redistribution (Alesina et al., 1999; Luttmer, 2001). Finally, the historical experience

\footnotetext{
${ }^{17}$ The intuition is based on the median-voter hypothesis (e.g. Meltzer and Richard, 1981), which basically states that the demand for redistribution is greater, the larger the inequality before taxes and transfers. Moreover, note that treating the before taxes-and-transfer inequality may be elusive because, for example, labor market regulations and institutions obviously have an impact on the before tax-and-transfer income distribution and are likely to be associated with individuals' redistributive preferences.
} 
of having been exposed to socialist ideology and rule may have had a long-lasting impact on both (the functioning of) institutions and as well as on individuals' trust in these institutions (e.g. Alesina and Fuchs-Schündeln, 2007).

Based on these considerations I run a simple variation of the baseline regression specification from before:

$$
\omega_{j t}=\beta_{0}+\bar{R}_{j t} \beta_{1}+x_{j t} \beta+\lambda_{t}+\epsilon_{j t}
$$

which corresponds exactly to equation (6a), with the exception that I now take additional country characteristics $x_{j t}$ as well as survey-year fixed effects $\lambda_{t}$ into account. Moreover, for the sake of brevity, I focus on redistributive preferences as main regressor in this part of the analysis. More specifically, based on the arguments above, I include the following set of country-level controls in all specifications: ${ }^{18}$ the population share aged 65 or over, openness to trade, a binary indicator for proportional representation, an index of ethnic fractionalization, and a binary indicator for countries that were formerly under socialist rule. The Gini coefficient of disposable household income before taxes and transfers is only included in one of the specifications for the Gini coefficient after taxes and transfers. ${ }^{19}$

\section{Table 5}

The resulting parameter estimates are given in table 5. The dependent variable in the first specification is again the difference between the Gini coefficient before and after taxes and transfer payments, $\Delta$ Gini. Controlling for additional country characteristics, the coefficient on $\bar{R}_{j t}$ turns out to be much smaller than in the baseline specification (see table 3 ). The resulting point estimate equals -0.049 , which is statistically insignificant (t-value of -0.271). In contrast, however, there is a significant negative coefficient of ethnic fractionalization and a significant positive coefficient of the dummy variable for former socialist countries. The other coefficients

\footnotetext{
${ }^{18}$ See appendix table A.1 for details and data sources.

${ }^{19}$ In the case of $\Delta$ Gini, there is a correlation with Gini $_{\text {before }}$ simply by construction. Moreover, one may argue that the Gini coefficient before taxes/transfers is endogenous and should rather be viewed as an additional outcome (cf. footnote 17). Similarly, average income in a country is arguably endogenous, and I thus only discuss estimation results without controlling for per-capita income, but I get very similar results if I also control for a country's average income (i.e. log per-capita GDP).
} 
turn out to be statistically insignificant as well. Moreover, note that the model fit is nonetheless good in the sense that the model has good predictive power overall (R-squared of 0.57 with six regressors only).

The second column replicates the specification from the first column, but uses total social expenditure as dependent variable. Similarly, the coefficient on redistributive preferences becomes insignificant once additional country characteristics are taken into account. The point estimate is only about a quarter of the baseline estimate from table 3 above, with a small t-value of 0.522. Again, most other regressors turn out be insignificant as well, with the exception of the percentage share of the country' population that is aged 65 or above in this case.

The remaining three columns show results for the Gini in disposable household income after taxes and transfer payments. The third column shows a small and insignificant estimate on redistributive preferences $\left(\widehat{\beta_{1}}=-0.061\right.$, with a t-value of -0.356$)$ as well as on the Gini before taxes and transfers when additional controls are included. The fourth column again shows that virtually the same point estimates result if the Gini coefficient in disposable household income before taxes and transfers is omitted from the list of controls (point estimate of -0.101, t-value of -0.652). Finally, the fifth column shows results for the same specification but for the slightly larger sample (as in the baseline estimates). Parameter estimates again turn out to be very similar. The coefficient on redistributive preferences remains small and statistically insignificant (the corresponding point estimate equals 0.054 , with a t-value of about 0.5 ).

\section{Conclusions}

This paper shows that there is considerable variation in individuals' inequality perceptions, distributional norms, and redistributive preferences, both within and across countries/regions. Not surprisingly, individuals from European countries tend to demand more redistribution than those from Anglo-American countries. However, the descriptive analysis also shows that there is considerable heterogeneity across different countries from within Eastern or Western Europe or among the group of Anglo-American countries. There is also evidence of substantial upward shifts in both inequality perceptions and distributional norms over time (i.e. a shift towards more tolerance vis-à-vis inequality in market wages). 
However, the main focus of the empirical analysis is on the empirical association between the two subjective inequality measures and redistributive preferences on the one hand, and measures of the effective level of inequality and redistribution on the other hand. I find that both differences in subjective inequality indices and redistributive preferences are strongly and significantly associated with objective measures of inequality and redistribution, in line with the hypothesized equilibrium between redistributive preferences the effective supply of redistribution of the theoretical models outlined in the introduction (e.g. Alesina and Angeletos, 2005; Bénabou and Tirole, 2006). There is also evidence that the subjective and objective dimension of inequality and redistribution are, at least in part, linked through individuals' more general political preferences. Indeed, and in line with the evidence of strong associations between subjective and objective inequality measures, individuals with stronger redistributive preferences tend to be more likely to be in favor of state intervention in order to reduce the level of inequality, more likely to be supportive of progressive taxation, as well as less likely to state a conservative general political orientation.

I finally show that the simple association between redistributive preferences and the effective level of redistribution or after tax-and-transfer inequality vanishes if additional, and arguably more fundamental, country characteristics are taken into account. These additional results suggest that more fundamental and more deeply rooted country characteristics such as a country's political institutions explain both country differences in redistributive preferences (or, alternatively, differences in inequality perceptions and distributional norms) as well as country differences in the effective level of after-tax/transfer inequality and the effective extent of redistribution. 


\section{References}

Alesina, A. and Angeletos, G.-M. (2005). Fairness and Redistribution. American Economic Review, 95(4), 960-980.

Alesina, A. and Fuchs-Schündeln, N. (2007). Good-bye Lenin (or not?): The effect of communism on people's preferences. American Economic Review, 97(4), 1507-1528.

Alesina, A. and Giuliano, P. (2009). Preferences for Redistribution. NBER Working Paper No. 14825.

Alesina, A. and Glaeser, E. (2004). Fighting Poverty in the US and Europe: A World of Difference. Oxford University Press.

Alesina, A. and La Ferrara, E. (2005). Preferences for Redistribution in the Land of Opportunities. Journal of Public Economics, 89(5-6), 897-931.

Alesina, A., Baqir, R., and Easterly, W. (1999). Public Goods and Ethnic Divisions. Quarterly Journal of Economics, 114(4), 1243-1284.

Alesina, A., Glaeser, E., and Sacerdote, B. (2001). Why doesn't the united states have a european-style welfare state? Brookings Papers on Economic Activity, 2001(2), 187-254.

Atkinson, A. (2003). The changing distribution of income: evidence and explanations. German Economic Review, 1(1), 3-18.

Atkinson, A. (2008). The Changing Distribution of Earnings in OECD Countries. Oxford University Press.

Bénabou, R. and Tirole, J. (2006). Belief in a Just World and Redistributive Politics. Quarterly Journal of Economics, 121(2), 699-746.

Borck, R. (2007). Voting, Inequality and Redistribution. Journal of Economic Surveys, 21(1), 90-109.

Borge, L. and Ratts $\varnothing$, J. (2004). Income distribution and tax structure: Empirical test of the Meltzer-Richard hypothesis. European Economic Review, 48(4), 805-826.

Corneo, G. and Grüner, H. P. (2002). Individual Preferences for Political Redistribution. Journal of Public Economics, 83, 83-107.

Doerrenberg, P. and Peichl, A. (2012). The impact of redistributive policies on inequality in oecd countries. IZA Discussion Paper No. 6505.

Fong, C. (2001). Social Preferences, Self-Interest and the Demand for Redistribution. Journal of Public Economics, 82, 225-246.

Galasso, V. and Profeta, P. (2007). How does ageing affect the welfare state? European Journal of Political Economy, 23(2), 554-563.

Gastwirth, J. and Glauberman, M. (1976). The Interpolation of the Lorenz Curve and Gini Index from Grouped Data. Econometrica, 44(3), 479-483. 
Isaksson, A. and Lindskog, A. (2009). Preferences for redistribution-A country comparison of fairness judgements. Journal of Economic Behavior $\& 5$ Organization, 72(3), 884-902.

Jasso, G. (1980). A New Theory of Distributive Justice. American Sociological Review, 45(1), $3-32$.

Kuhn, A. (2011). In the eye of the beholder: Subjective inequality measures and individuals' assessment of market justice. European Journal of Political Economy, 27(4), 625-641.

Levy, F. and Temin, P. (2007). Inequality and Institutions in 20th Century America. NBER Working Paper No. 13106.

Luttmer, E. (2001). Group loyalty and the taste for redistribution. Journal of Political Economy, 109(3), 500-528.

Meltzer, A. H. and Richard, S. F. (1981). A Rational Theory of the Size of Government. Journal of Political Economy, 89(5), 914-27.

Milanovic, B. (2000). The median-voter hypothesis, income inequality, and income redistribution: an empirical test with the required data. European Journal of Political Economy, 16(3), 367-410.

OECD (2008). Growing Unequal? Income Distribution and Poverty in OECD Countries. Technical report, OECD.

Osberg, L. and Smeeding, T. (2006). "Fair" Inequality? Attitudes toward Pay Differentials: The United States in Comparative Perspective. American Sociological Review, 71(3), 450473.

Piketty, T. (1995). Social mobility and redistributive politics. Quarterly Journal of Economics, 110(3), 551-584.

Piketty, T. and Saez, E. (2006). The evolution of top incomes: a historical and international perspective. American Economic Review, 96(2), 200-205.

Ravallion, M. and Lokshin, M. (2000). Who wants to redistribute? The tunnel effect in 1990s Russia. Journal of Public Economics, 76(1), 87-104.

Razin, A., Sadka, E., and Swagel, P. (2002). The aging population and the size of the welfare state. Journal of Political Economy, 110(4), 900-918.

Rodrik, D. (1998). Why do more open economies have bigger governments? Journal of Political Economy, 106(5), 997-1032.

Tabellini, G. (2000). A positive theory of social security. Scandinavian Journal of Economics, $\mathbf{1 0 2}(3), 523-545$. 


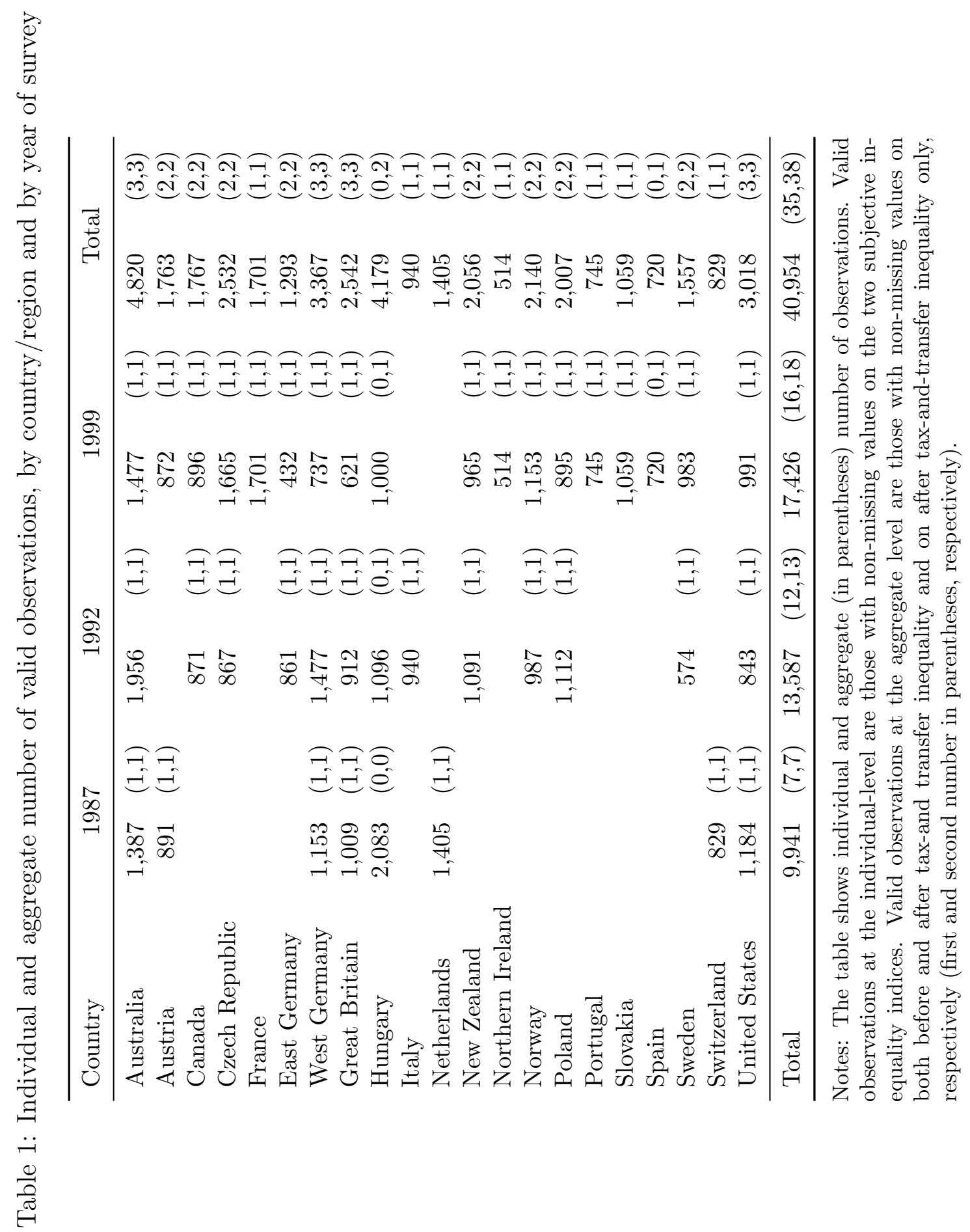




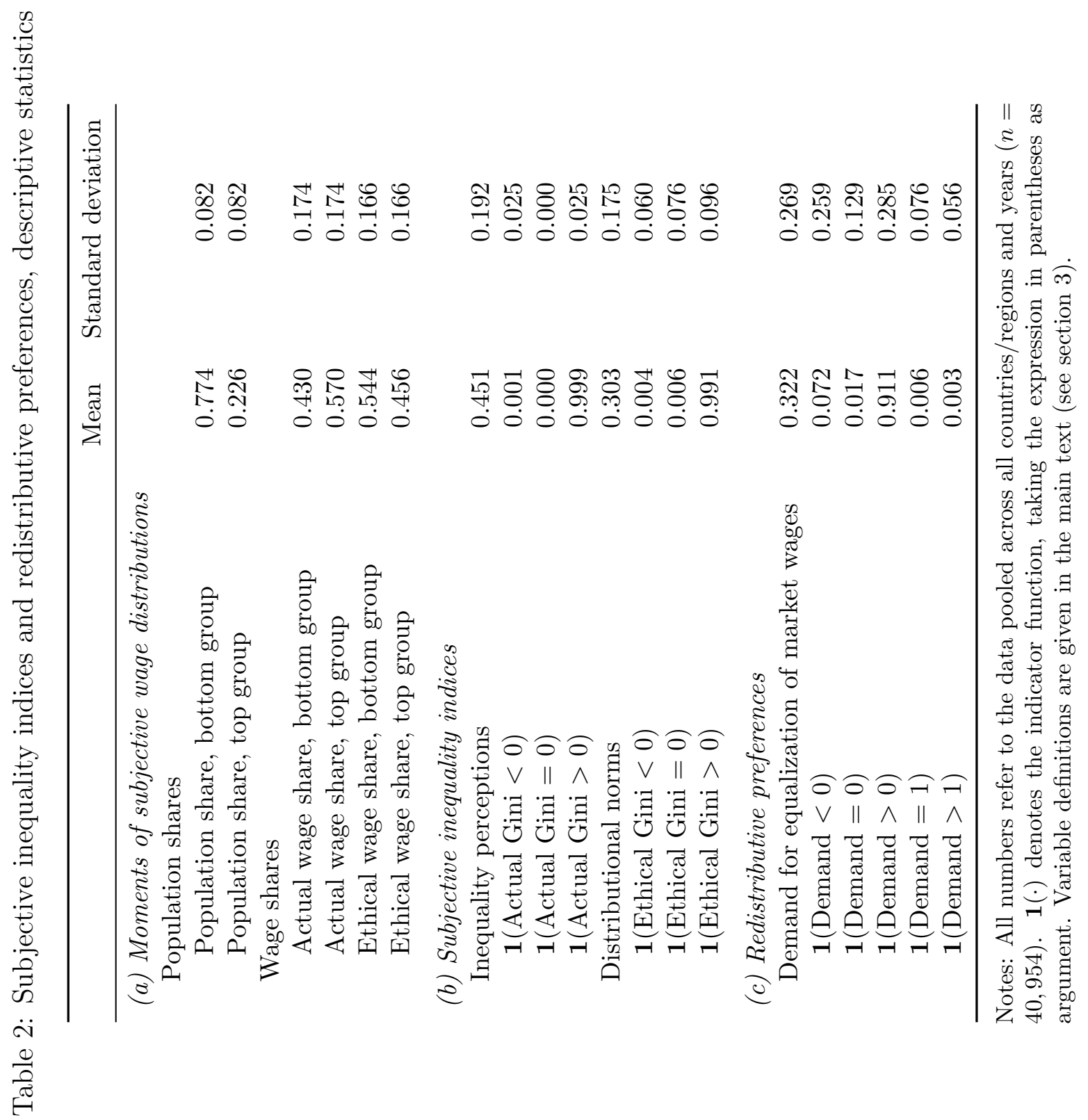




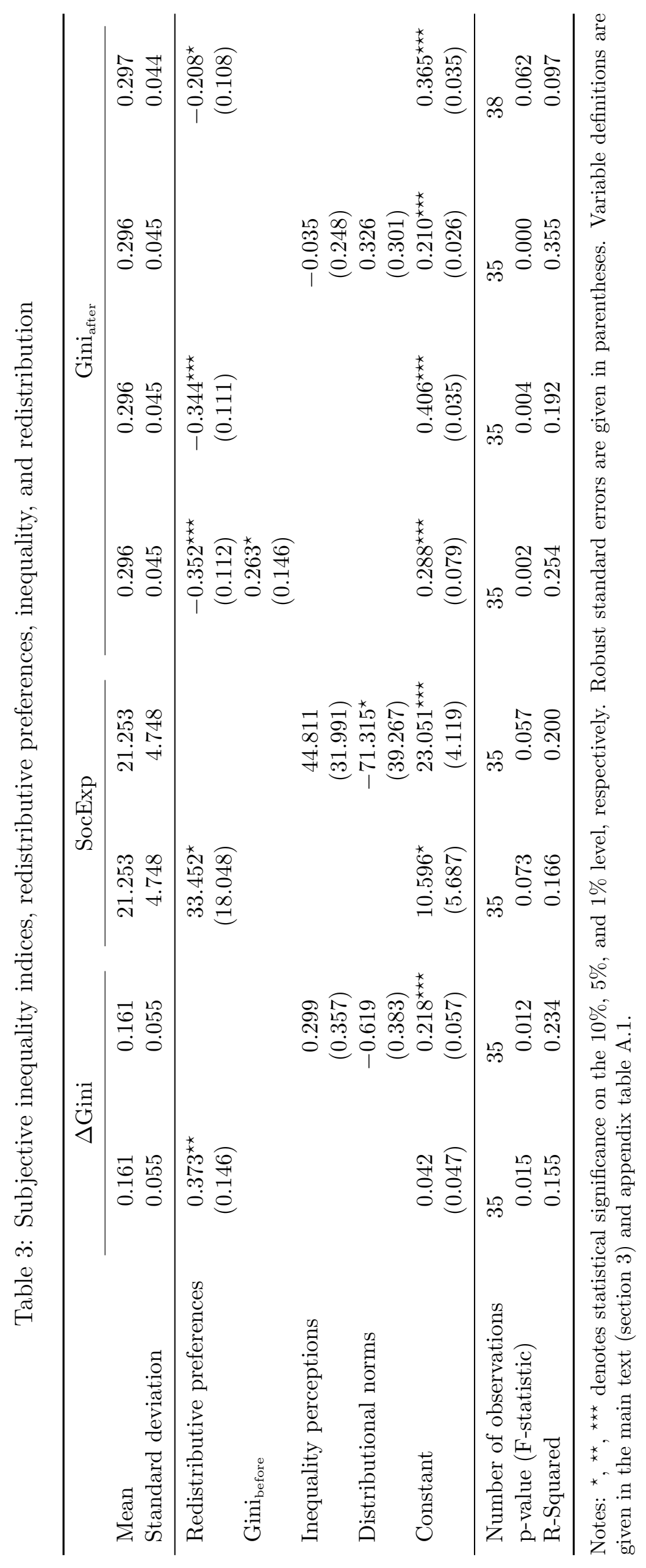




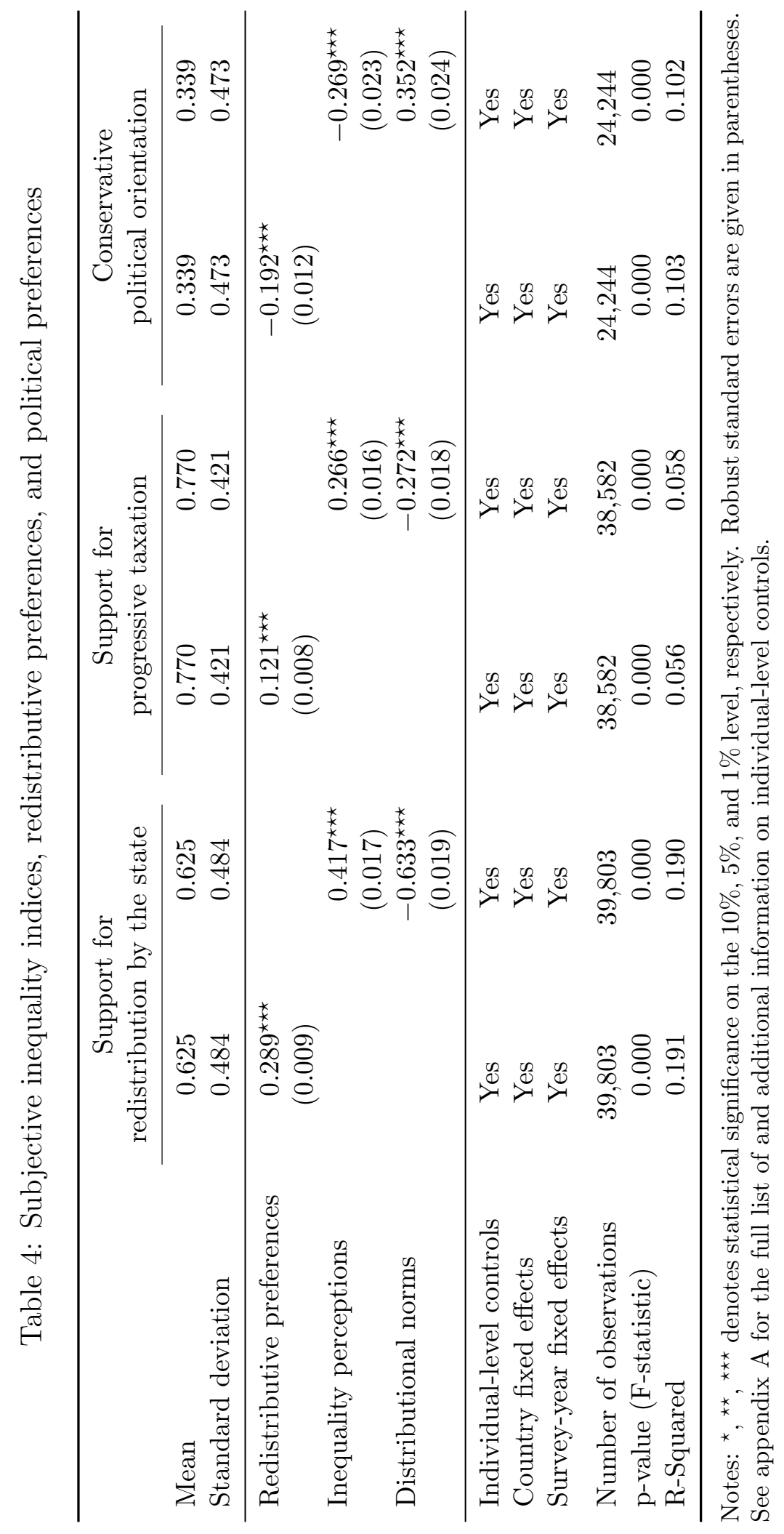




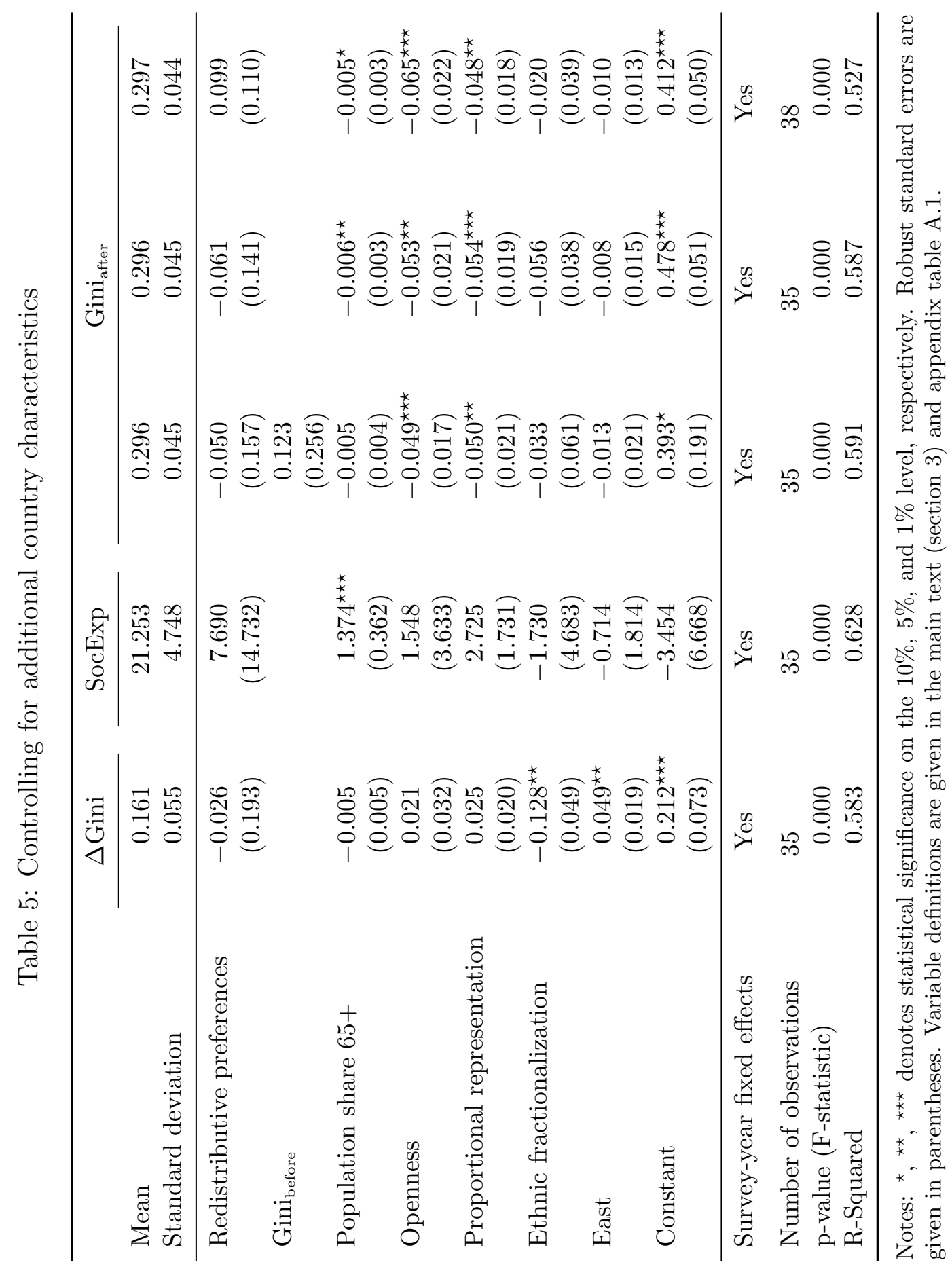



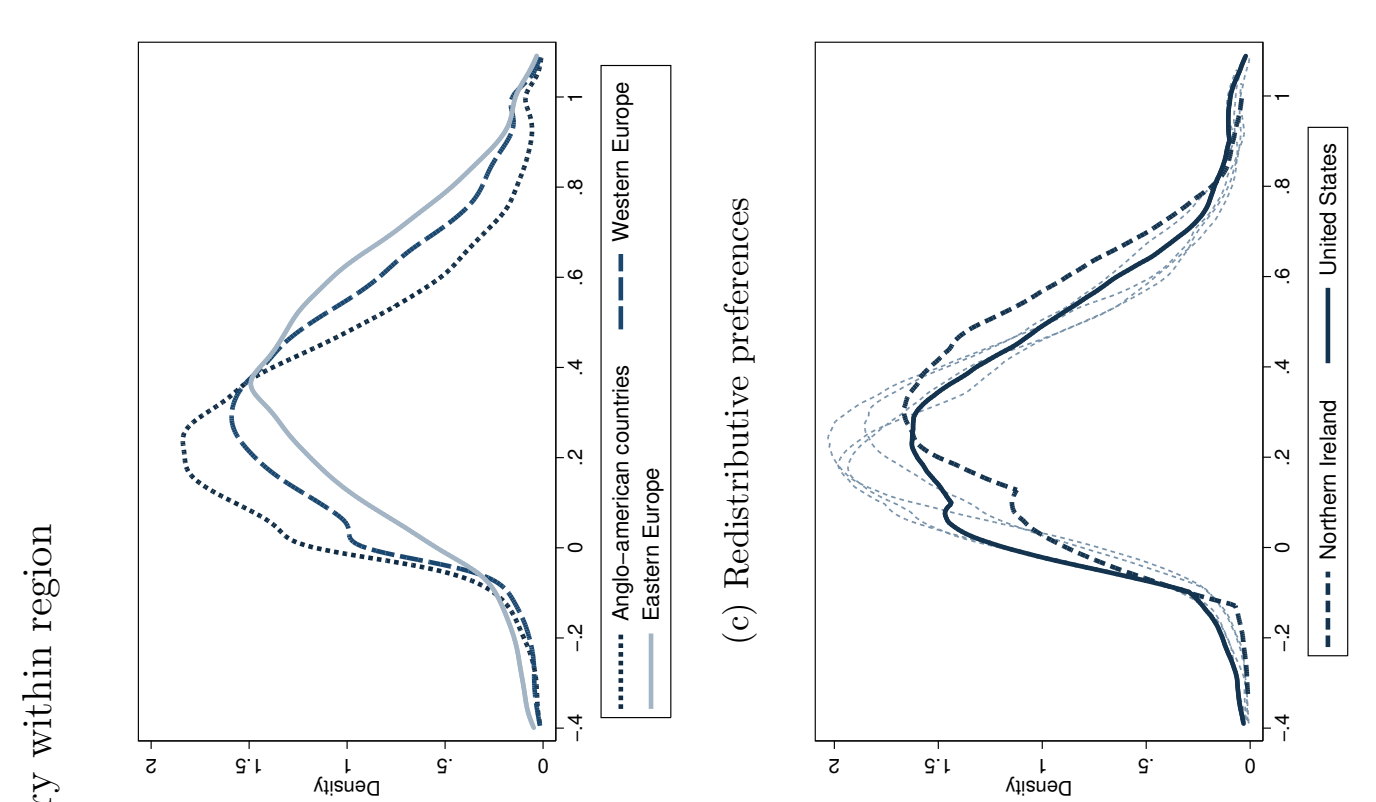

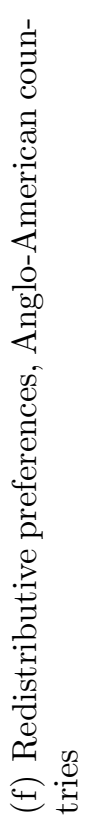

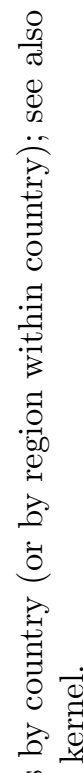

营
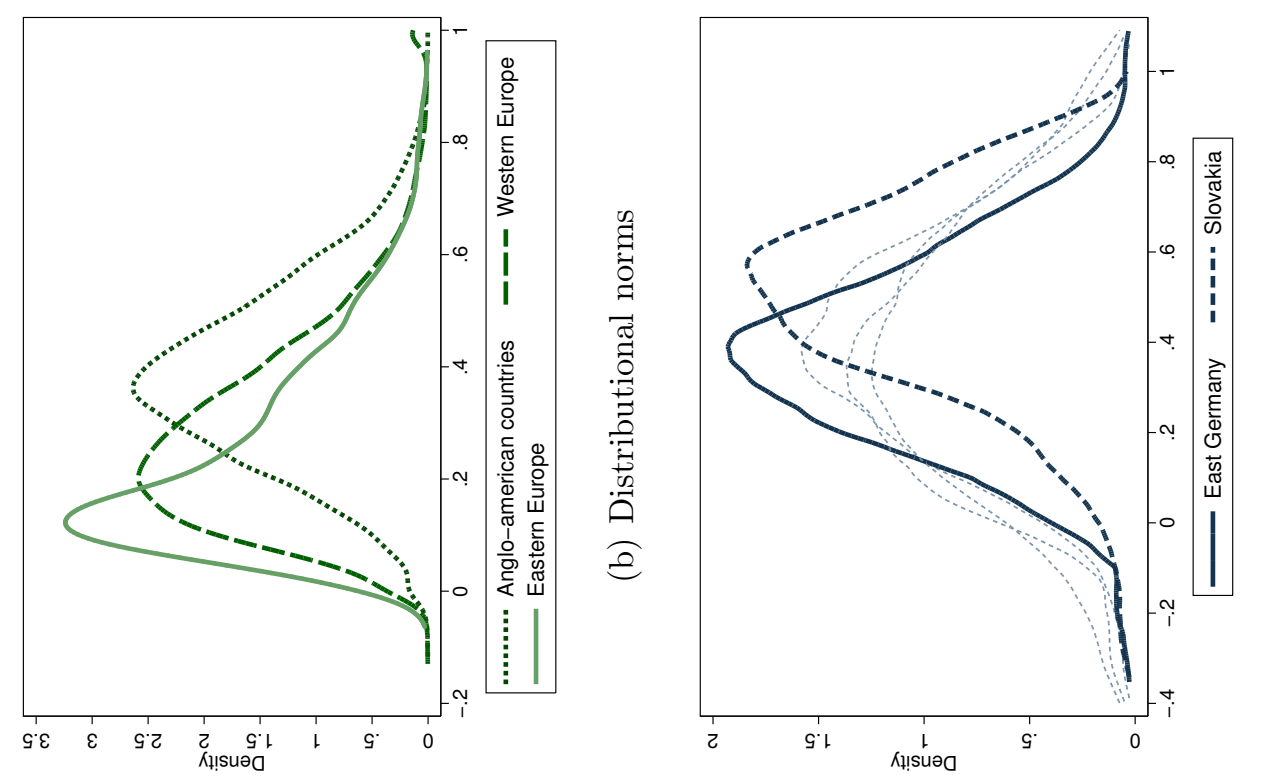

造

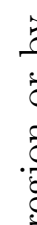

合

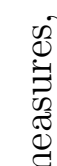

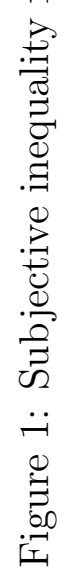
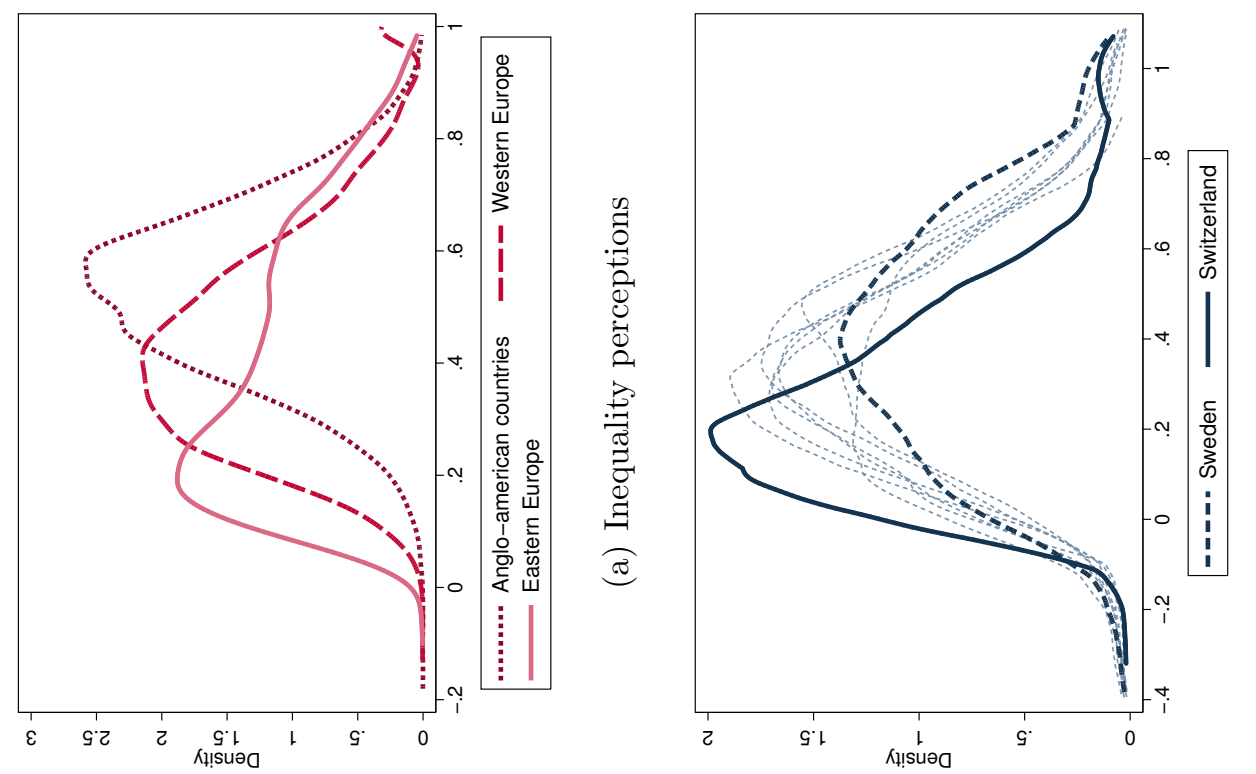

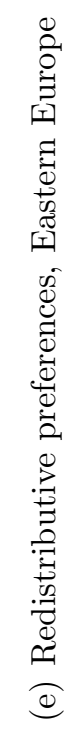

预

过

क⿺⿻一⿰冫⿰亅⿱丿丶丶⿱⿰㇒一乂

ब्ञ .7

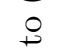

을

讨

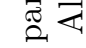

คิ

है

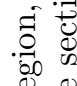

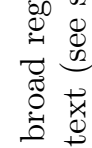

家

売

苟 莺.

3 .

ङ

敞

记

害要

ब)

包. 


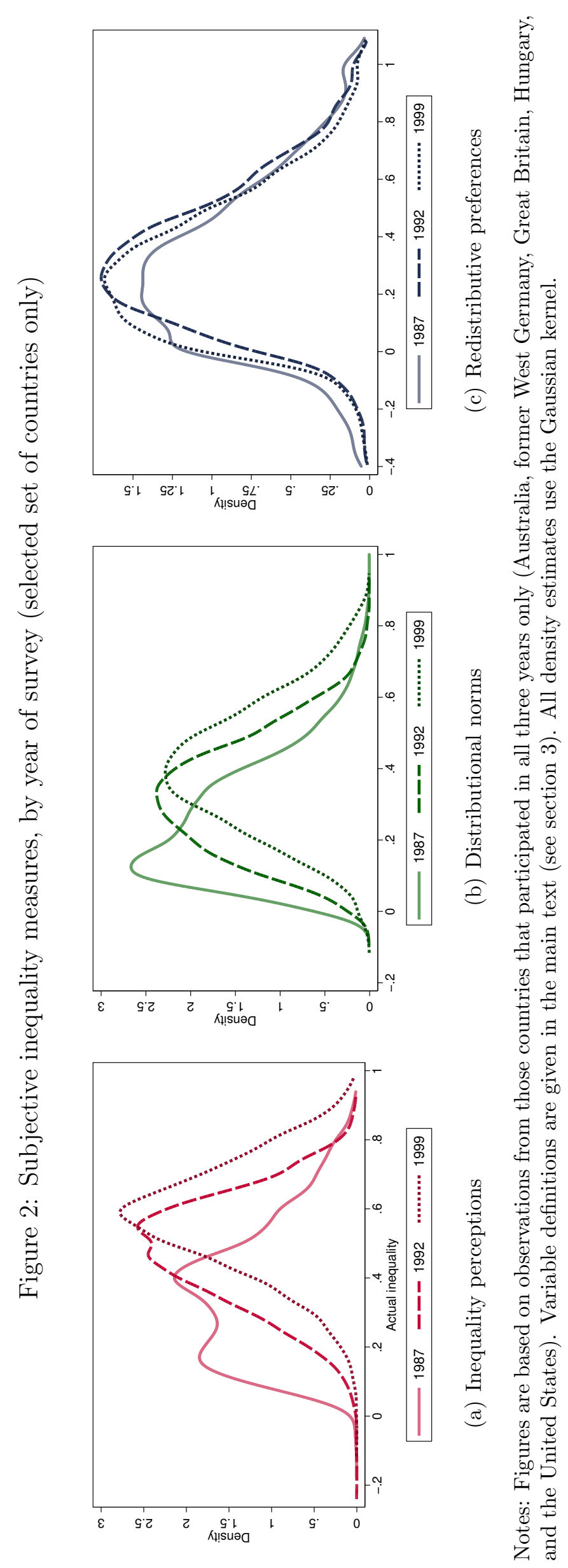




\section{A Variable Definitions and Data Sources}

\section{A.1 Aggregate-level Variables}

Inequality and redistribution Mainly due to reasons of data availability, I focus on the Gini coefficients in disposable household income before and after taxes and transfer payments. I further use either the difference between the two Gini coefficients or overall social expenditure (as a percentage share of GDP) as my measure of redistribution.

Aggregate-level controls In the aggregate-level regressions (see section 5.3), I include the percentage share of the population aged 65 or above, a country's openness, an indicator if a country has proportional representation, an index of ethnic fractionalization, and an indicator if a country was under socialist rule after World War II. See table A.1 for details.

\section{A.2 Political Preferences}

Support for redistribution through the state: Individuals' support for redistribution by the state is measured by a simple item from the survey: "Do you agree or disagree? It is the responsibility of the government to reduce the differences in income between people with high incomes and those with low incomes." The possible answers range from 1 ("strongly disagree") to 5 ( "strongly agree"). In the empirical analysis, I simply use a dichotomized variable taking on the value 1 if an individual (strongly) agrees with the statement and 0 otherwise.

Support for progressive taxation: Individuals' support for progressive taxation is measured by a single survey item: "Do you think people with high incomes should pay a larger share of their income in taxes than those with low incomes, the same share, or a smaller share?" Possible answers range from 1 ("much smaller share") to 5 ("much larger share"). In the analysis, I again use a dichotomized variable taking on the value 1 if an individual states that people with high incomes should pay a (much) larger share, and 0 otherwise.

Conservative orientation: Individuals' stated political orientation on a simple left-right scale. "Based on your current voting intention, would you consider yourself left-wing or rightwing?" Possible answer categories range from 1 ( "far left") to 5 ( "far right"). In the analysis I use a dichotomized variable taking on the value 1 if an individual calls him- or herself (far) right.

\section{A.3 Individual-level Regressors}

I use three sets of regressors to model the variation in individuals' more general political preferences (section 5.2): (i) variables which describe the factors that do or ought to determine actual pay from the individuals' point of view, (ii) variables describing individuals' self-interest in redistribution or economic variables mediating self-interest in redistribution, and (iii) additional control variables which potentially correlate with unobserved determinants of subjective inequality measures (like risk aversion, for example).

Belief that needs should be important: This variable is meant to capture the extent to which an individual thinks that one's needs should be important in determining his or her income (need principle). This variable is constructed from the following two questions about 
the factors that should be important in determining one's pay: "In deciding how much people ought to earn, how important should each of these things be, in your opinion? (i) What is needed to support your family. (ii) Whether the person has children to support."

Belief that effort should be important: This variable is meant to capture the equity principle and is constructed from five questions about which factors should be important in determining pay: "In deciding how much people ought to earn, how important should each of these things be, in your opinion? (i) How much responsibility goes with the job. (ii) The number of years spent in education and training. (iii) Whether the job requires supervising others. (iv) How well he or she does the job. (v) How hard he or she works at the job."

Perception that ascribed skills are important: This variable measures the extent to which a person beliefs in ascribed factors as being important in determining the amount of compensation. This question relates to the perception of individuals of which factors actually are important for getting ahead. "We have some questions about opportunities for getting ahead: (i) How important is coming from a wealthy family? (ii) Knowing the right people?"

Perception that acquired skills are important: This variable measures if an individual thinks that acquired skills are actually important in determining one's pay. The variable is the sum of over two different questions: "We have some questions about opportunities for getting ahead: (i) Do you agree or disagree? In [country], people get rewarded for their effort. (ii) In [country], people get rewarded for their intelligence and skills."

Income: An individual's personal net monthly income, expressed as the rank of an individual within the income distribution in a given country and year (to remove different scaling).

Social mobility: There are two simple questions about individuals' self-perception of the position today and ten years ago: "(i) In our society, there are groups which tend to be towards the top and groups which tend to be toward the bottom. Below is a scale that runs from top to bottom. Where would you put yourself on this scale? (ii) And ten years ago, where did you fit then?" Both are measured on a scale from 1 (bottom) to 10 (top). The mobility index is simply defined as the difference between the two scores (i.e. position today minus position ten years ago).

Perception of social conflicts: This variable measures individuals' perceptions of conflicts within society. Included items are questions about the existence of conflicts between: "In all countries, there are differences or even conflicts between different social groups. In your opinion, In [country] how much conflict is there between...: (i) Poor people and rich people? (ii) The working class and the middle class? (iii) Management and workers? (iv) People at the top of society and people at the bottom? (v) Young people and older people?"

Socio-demographic controls: The remaining controls that are used in the analysis are self-explanatory: Age (in years), highest attained education (in years), gender, occupation (dummy variables denoting major occupational group according to the International Standard Classification of Occupations), and employment status (employment, unemployment, and nonemployment). 


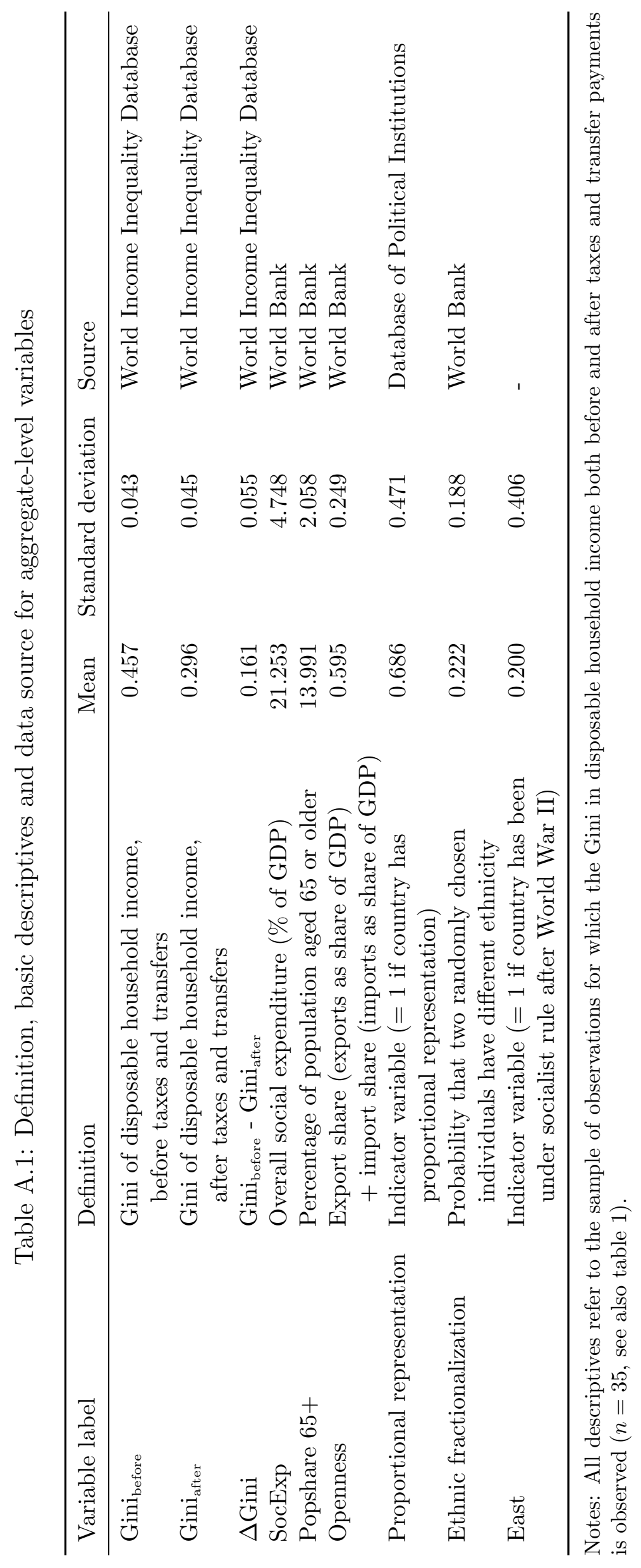




\section{B Estimating the Components of Subjective Gini Coef- ficients}

\section{B.1 Subjective Wage Estimates}

The most fascinating data available in the ISSP surveys focusing on social inequality are individuals' subjective estimates of actual and ethical wages for people working in various specific occupations such as a bus driver, a skilled worker in a factory, or a doctor in general practice. More specifically, individuals were asked to estimate what they thought to be the actual wage of people working in different occupations and what they thought people in these occupations ought to be paid from their point of view, denoted as actual and ethical wage estimates for short in the following (original wording from the source questionnaire):

"We would like to know what you think people in these jobs actually earn. Please write how much you think they actually earn each month (before taxes, but after social security contributions). Many people are not exactly sure about this, but your best guess will be close enough."

"Next, what do you think people in these jobs ought to be paid. How much do you think they should earn each month (before taxes, but after social security contributions), regardless of what they actually earn."

Table B.1 contains the full list of occupations for which subjective wage estimates are available (along with the original description of the various occupations in the survey). In the following I briefly describe how I aggregate these wage estimates so that they fit equation (3a) and (3b), respectively. Additional details concerning the conceptual framework are available from Kuhn (2011).

\section{B.2 Group-Specific Wages}

I first assign each occupation for which individual wage estimates are available to either the bottom or the top group of wage earners:

$$
\begin{aligned}
\text { bottom }= & \{\text { unskilled worker, farm worker, shop assistant, secretary, bank clerk, } \\
& \text { bus driver, skilled worker, bricklayer, owner of a small shop }\} \\
\text { top }= & \{\text { doctor, lawyer, minister, judge, chairman, owner of a factory }\}
\end{aligned}
$$

Based on this simple classification, group-specific wage estimates (actual and ethical) are constructed as simple within-group averages of occupation-specific wage estimates:

$$
\begin{aligned}
\bar{y}(i)_{\mathrm{bottom}}^{w} & =\frac{\sum_{j=1}^{15} \mathbf{1}(j \in \operatorname{bottom}) y(i)_{j}^{w}}{\sum_{j=1}^{15} \mathbf{1}(j \in \operatorname{bottom}) \mathbf{1}\left(y(i)_{j}^{w} \neq *\right)}, \quad \text { and } \\
\bar{y}(i)_{\mathrm{top}}^{w} & =\frac{\sum_{j=1}^{15} \mathbf{1}(j \in \operatorname{top}) y(i)_{j}^{w}}{\sum_{j=1}^{15} \mathbf{1}(j \in \operatorname{top}) \mathbf{1}\left(y(i)_{j}^{w} \neq *\right)},
\end{aligned}
$$

with $y(i)_{j}^{w}$ denoting an individual's actual or ethical wage estimate for people working in occupation $j$, with $w \in\{$ actual, ethical $\}$, and with $*$ denoting a missing wage estimate. As indicated by the second indicator function in the denominator, group-specific wages can be computed for any single individual as long as he or she gives at least one wage estimate per group (i.e. at 
least one wage estimate for the top group and at least one estimate for the bottom group). This procedure can also easily take care of the fact that the list of occupations has changed over time and that wage estimates for all fifteen occupations are available only in 1992 and only for a few countries (see appendix table B.1).

\section{B.3 Fraction of Individuals Belonging to the Bottom Group}

Finally, the fraction of individuals belonging to the bottom group is estimated from the distribution of individuals across occupations in the sample:

$$
f_{\text {bottom }}=\frac{1}{n} \sum_{i=1}^{n} \mathbf{1}\left(\text { isco }_{i} \in[3,9]\right),
$$

with isco $_{i}$ denoting an individual's major occupational code according to the International Standard Classification of Occupations (ISCO). According to this classification, major group 1 consists of "legislators, senior officials and managers" and major group 2 of "professionals". Note that I estimate a different $f_{\text {bottom }}$ for each pair of country and year. As mentioned above, however, within any pair of country $\times$ year the size of the two groups is the same for all individuals and the same for both the distribution of actual and ethical wages. In fact, however, estimated group shares do not change much over time and thus results would hardly change if I would allow the population shares to vary only across countries only (but not over time). 


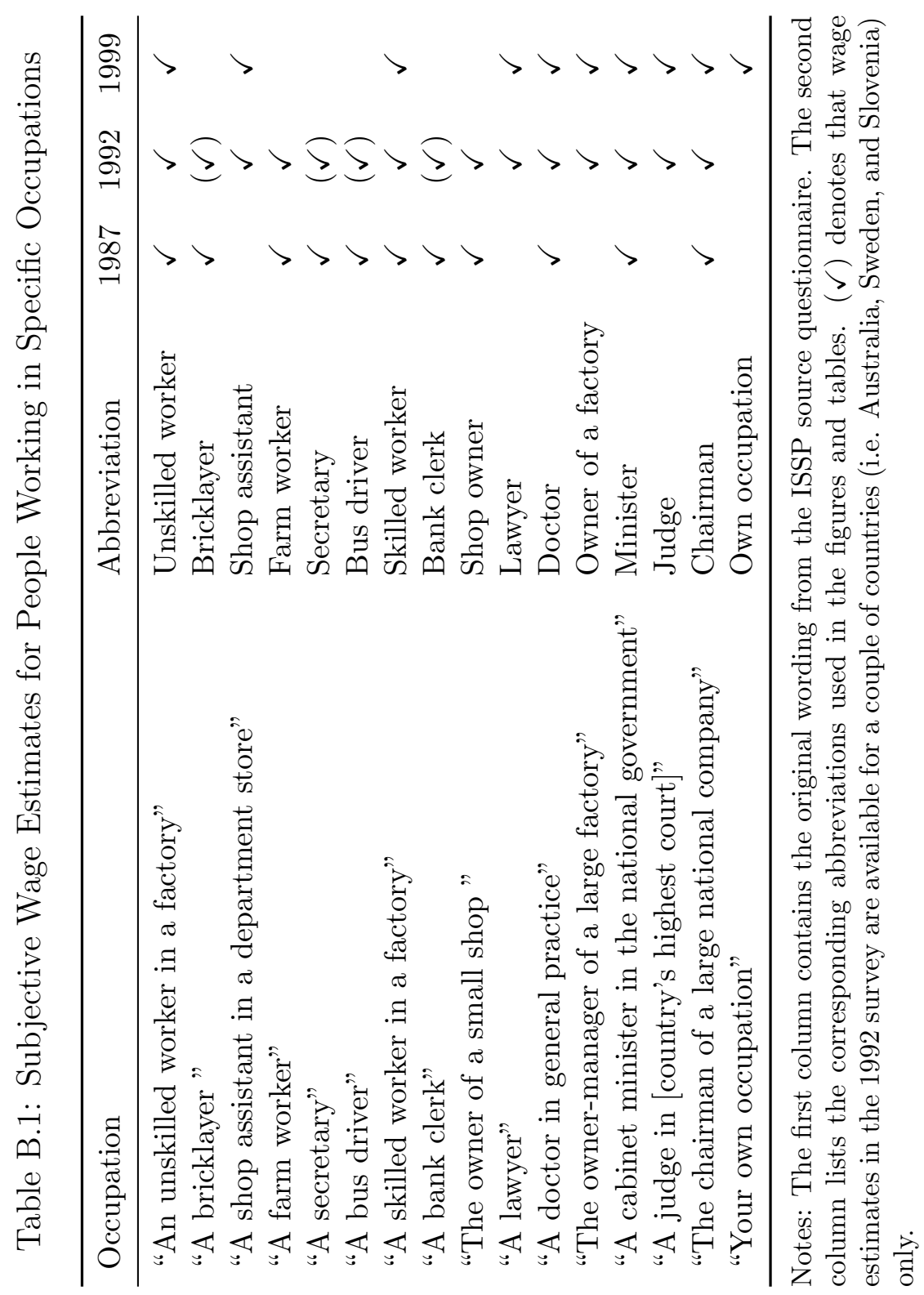

